


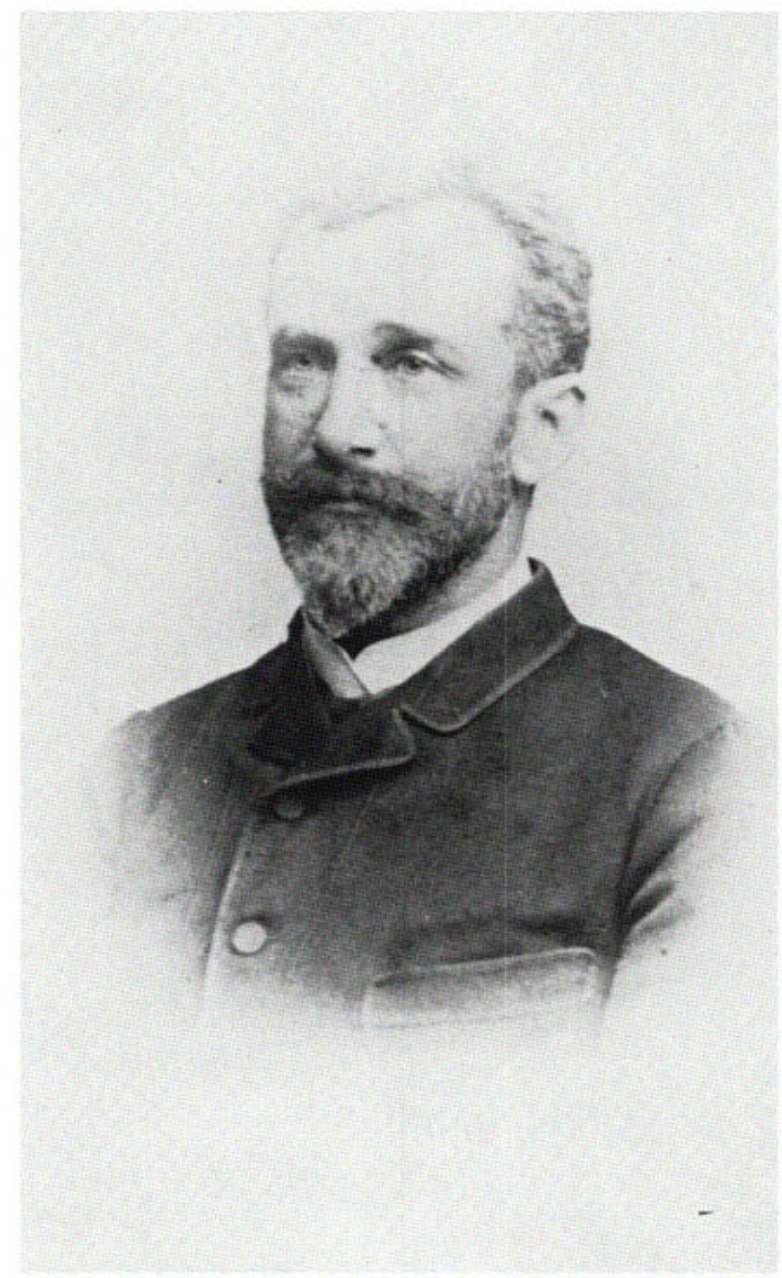

JULIUS ZEYER

from a photograph by J. Mulač, Prague, Ovocná 15 


\section{JULIUS ZEYER}

\section{The Path to Decadence}

by

ROBERT B. PYNSENT

School of Slavonic and East European Studies

University of London

1973

MOUTON

THE HAGUE - PARIS 
(C) Copyright 1973 in The Netherlands

Mouton \& Co. N.V., Publishers, The Hague

No part of this book may be translated or reproduced in any form by print, photoprint, microfilm, or any other means, without written permission from the publishers

LIBRARY OF CONGRESS CATALOG CARD NUMBER: 73-83427

Printed in The Netherlands by Mouton \& Co., The Hague 